Économie internationale 109 (2007), p. 31-51.

\title{
A RE-EVALUATION OF THE IMPACT OF REGIONAL AGREEMENTS ON TRADE PATTERNS
}

\author{
Lionel Fontagné \& Soledad Zignago ${ }^{1}$
}

\begin{abstract}
This article analyses the trade impact of preferential trade agreements (PTA). We firstly revisit the literature using a "traditional gravity" setting extended to rely on detailed data at the sector level (26 ISIC industries), using a panel of more than 100 countries between 1976-2000. Secondly we use the border effect methodology. Lastly, dyadic fixed effects make it possible to control for unobserved characteristics of country pairs, hence for the endogeneity of the PTA. We systematically disentangle the various arrangements and tentatively introduce tariffs. The positive trade impacts of the EU, NAFTA and ASEAN are downsized by such improvements.
\end{abstract}

JEL Classification: F12; F15. Keywords: Regional Integration; Border Effects; Gravity.

RÉSUMÉ. Cet article approfondit l'analyse de l'impact commercial de la signature d'un accord préférentiel. Tout d'abord nous réexaminons les résultats de cette littérature en testant des équations gravitaires traditionnelles mais en exploitant la dimension industrielle de notre base de données de commerce, production et protection bilatérale couvrant plus de cent pays, 26 industries CITI, pour la période 1976-2000. Nous comparons ces résultats avec ceux obtenus en utilisant la méthodologie des effets frontière qui a un fondement théorique solide et offre un référentiel de l'intégration commerciale plus convaincant, les flux ayant lieu à l'intérieur d'une nation, espace supposé parfaitement intégré. Enfin, l'introduction d'effets fixes par couples de pays permet de tenir compte des caractéristiques inobservables reliant les pays qui entrent dans l'accord et réduit largement les effets estimés de la signature d'un accord sur les échanges entre pays membres, notamment pour I'UE mais aussi pour I'ALENA et I'ASEAN.

Classification JEL : F12; F15

Mots-clés : Intégration régionale ; effets frontières; gravité.

1. Corresponding author: Soledad ZIGNAGO,Economist, CEPII (soledad.zignago@cepii.fr).

Lionel Fontagne, Professor of Economics, Université Paris I Panthéon Sorbonne, Paris School of Economics and Scientific Advisor, CEPII. 


\section{— INTRODUCTION}

The influence of regional agreements on trade patterns has been the primary subject of the huge literature using gravity equations to study bilateral volumes of trade. There are dozens of papers in this literature dating back to the early seventies, that is soon after the gravity equation had been applied to international trade for the first time. The exceptional fit of simple linear (in logs) regressions involving three core variables for which data are among the easiest to find, clearly contributed to the initial and persistent success. Researchers investigated almost all possible preferential trading agreements (PTA), looking for positive deviations from the "norm of trade" given by gravity.

For a while, technical progress in this area has mostly consisted in adding covariates that were found to improve the fit of the regression, various measures of countries' geographical, historical and cultural proximity have been added to the set of explanatory variables, in an objective to provide better control for unobserved characteristics of the bilateral trade between two countries. This is indeed important for the assessment of the impact of PTAs. For instance, most PTAs involve a large proportion of contiguous countries. Omitting this variable, while putting a PTA dummy in a cross section regression can generate fallacious positive estimates on trade policy due to an omitted variable bias. ${ }^{2}$

More recently, decisive progress has been made in the link between the empirical gravity equation and the different modeling frameworks available in trade theory. Many authors had tried to take into account the remoteness of trading partners, that is not only their bilateral distance, but also their location with respect to third countries. Recent work by several economists (surveyed in Feenstra, 2003) has helped to make sense of those ad hoc attempts, in deriving the gravity equation rigorously from trade theory and providing a clear description of what a correct econometric specification should be. Here again the matter is important for obtaining a valid estimate of the impact of a PTA. To take only an example, do Australia and New Zealand trade a lot with themselves because of their common remoteness from easy alternative source of products and markets to exports, or because of their preferential trading arrangement? The improved link with theory enables to sort those out by radically improving the norm of trade to which exchanges within a PTA is compared.

Even with those progresses, one has to think about the reference group to which members of a PTA are compared when doing such an exercise. Indeed, the endogeneity of the membership decision has been recently demonstrated by Baier and Bergstrand (2004), and the choice of the control group to evaluate the impact of the PTA is not an easy task. Furthermore, results of this literature exhibit disconcerting variance, with widely varying

2. It might however be argued that even the recent associated literature is relying on relatively little and sometimes incredibly poor data: GDP (sometimes replaced with population), distance, and a set of geographical dummies often with no time variance. The sectoral dimension of the problem is usually completely omitted; tariffs are almost never controlled for (not to mention less visible trade policy measures). 
estimates among studies, troubling ranking of trade creating agreements, and other characteristics that contrast dramatically with the stability of the core gravity estimates.

There is therefore a need for revisiting the results of the literature assessing the trade effects of regional arrangements. In what follows, we tentatively have a threefold value added. Firstly, we rely on a new data set encompassing trade and production longitudinal data for a wide range of countries at the industry level. Secondly, we use a theory-based version of the gravity equation in order to address the misspecification issue, relying on the modeling structure of the border effects literature. Last, we try to progress on the reference group issue making use of this border effect methodology. We consider international trade inside a PTA not with respect to trade with third countries solely, but instead compare those two flows to a third one: trade within countries, which seems to be the natural benchmark of a perfectly integrated economy.

The rest of the paper is organized as follows. Section 2 reviews the traditional gravity estimate of the effects of PTAs, then lists the problems encountered in the literature, and lastly combines gravity plus sectoral panel data. Section 3 departs from the traditional gravity framework by relying on the right benchmark for economic integration, which is not trade with different foreign countries, but trade within countries. A theoretical framework is proposed, from which a trade equation in relative terms is developed. We use this setting to estimate border effects within and outside PTAs and accordingly derive results regarding the reduction of border effects associated with the different regional experiences. Section 4 addresses the endogeneity of PTAs: fixed effects by pairs of partners make it possible to control for unobserved bilateral variables affecting trade between countries and possibly determining whether these countries enter a preferential arrangement. Section 5 concludes.

\section{astimating the impact of PTAs WITH GRAVITY ESTIMATES}

\section{The basics}

The considerable literature estimating the trade impact of PTAs relies mostly on a dummy variable introduced in a gravity-type equation explaining the log of bilateral imports of country $i$ from country $j\left(M_{i j}\right)$ of the following type:

$$
\ln M_{i j}=\alpha+\beta_{1} \ln Y_{i}+\beta_{2} \ln Y_{j}+\beta_{3} \ln d_{i j}+\beta_{4} C_{i j}+\beta_{5} \mathrm{EU}_{i j}+\varepsilon_{i j}
$$

where the $Y$ terms (designating the GDPs of the two trade partners) and $d_{i j}$ (measuring the distance separating them) represent the "core" of the gravity equation. The core gravity variables explains most of the variance in bilateral exports. The $C_{i j}$ term represents a vector of control covariates, intended to refine the econometric exercise, in general through a better specification of transaction costs (most frequent variables are common language, contiguity and variables indicating colonial links). Income per capita is also often introduced to account for endowment differences. Last, researchers introduce a dummy variable for the 
PTA under investigation, the European Union in this example $\left(\mathrm{EU}_{i j}\right)$, taking the value of one if $i$ and $j$ are both member countries. The exponential of the coefficient on this variable is interpreted as the deviation from the trade norm due to the PTA: Everything else equal, $\exp \left(\beta_{5}\right)=\frac{M_{i j}}{M_{i k}}$, where $k$ is another country that does not belong to the EU.

\section{The myriad of problems associated with estimating the impact of PTAs on trade patterns}

The results of such estimations are not as clear as what would be expected. Take as an example the deepest and longest PTA experience, the EU. The evidence on the extent and evolution of European trade integration using gravity estimates is in fact surprisingly negative. Start by considering widely cited work by Jeffrey Frankel and co-authors. Table 2 in Frankel et al. (1995) and Table 4.2 in Frankel (1997) are very representative of their results for European trade integration. The least that can be said is that they are not very conclusive at first sight. Their coefficients on the EU dummy variables start to be significant in the mideighties and a typical estimate in 1990 is 0.5 , that is two member countries of the EC trade that year "only" $65 \%$ more $(\exp (.5)=1.65)$ than two otherwise similar country (based on a 63 times 63 matrix of total trade representing $88.7 \%$ of world trade in 1992). Even worse, when adding common language the coefficient is reduced by half and becomes insignificant when adding the general level of openness of European countries. Haveman and Hummels (1998) have very similar results for trade flows over the 1980-1992 period, with coefficients at 0.585 in 1980, 0.825 in 1986 and 0.406 in 1989. Soloaga and Winters (2001) compare a large number of regional agreements with the goal of identifying the evolution of regional agreement dummies over time and particularly around the periods of bloc formation/revival. Here again the sample is very large with 58 importing countries over the 1980-1996 period. The EC dummy is found to be consistently and very significantly negative. Worse, the economic magnitude of the effect seems to be very large. The coefficient starts at -1.78 in 1980 and is at -0.80 in 1996 (which at least shows some "integration" over time).

Some estimates are more in line with expectations, but the point here is that PTA coefficients using this standard method are not very stable, and sometimes contradict other empirical evidence on the actual trade liberalization taking place inside the different PTAs. The question we ask in this paper is how much of the problems in those results come in fact from flaws in the standard gravity equation estimation, in terms of econometric specification, and proper identification of the impact of PTAs.

Looking for the usual suspects is not an easy task. Firstly, the measurement error is potentially a key issue. There is here a difficulty associated with the time dimension of the PTA (when does it start? Are the effects delayed? Have economic agents anticipated this integration?); a dummy used in cross section can hardly be used with a great level of confidence. In addition, the depth of the integration will indeed profoundly affect the impact on trade patterns, which cannot be assessed on the basis of the traditional dummy variable for PTAs. 
Secondly, the simultaneity bias, associated with the fact that incomes of the exporting and importing countries are endogenous to trade flows might also be an issue. However, it is not a key concern: what we tackle is bilateral flows, not total flows, and only the net exports are at stake. Accordingly, instrumenting does not change significantly the results (Frankel, 1997).

It is also possible that the estimated impact of the PTAs will be influenced by an inadequate specification since, for instance, countries very isolated because of their physical geography will have at the same time few neighbors to sign PTAs with, and high price indexes which reduces their imports.

Lastly comes the endogeneity issue. The endogeneity problem is common in international trade: papers addressing the impact of non-tariff barriers on trade flows, for instance, will often find a positive impact at a sufficiently disaggregated level, because of the unobservable (e.g. political economy) variables (Trefler, 1993). But regarding the assessment of the impact of PTAs on trade patterns, this issue become crucial: Should we consider that France and Germany do trade a lot because they belong to the Single market? Or have they decided in the 50s to launch a process of integration just because they were "natural" trade partners? Clearly, the presence of a free trade agreement between two countries is not exogenous to their characteristics. Their geographical location (are they adjacent? Are they remote from the bulk of other markets?), their economic size (does each country offer to its counterpart a wide or a limited variety of goods and services?), a common history, a common culture, a common set of political institutions, are among the main characteristics impacting the probability of signing a PTA. One may object that the intensity of their actual bilateral trade relationship is also a key determinant. Endogenity issues come therefore both from omitted variables and reverse causality. Baier and Bergstrand (2004) instrument PTAs in various ways without solving the problem as long as the panel dimension of the data is not mobilized. Their interpretation of such result is that their instruments are in fact correlated with trade flows. Accordingly, cross-sectional estimates of the impact of PTAs should be avoided. Using panel data, they get more convincing and larger effects, which are definitively positive.

To sum up, there are a lot of issues to tackle, which define four data prerequisites for the econometric work, namely: panel data, preferably industry-level, best possible information on the different PTAs, and on other forms of trade policy, tariffs in particular. We now proceed to estimate a gravity equation adding some of those usually missing elements.

\section{Assessing properly the effects of PTAs: Gravity plus sectoral panel data}

In what precedes we have listed the prerequisites of a properly designed gravity equation. We now stick to the traditional gravity framework, extended to respect these prerequisites. To the best of our knowledge, even such a simple approach has not been systematized so far in the literature on PTAs. 
Firstly, we must rely on longitudinal data and hence exploit the panel dimension of our data set. Taking benefit of mirror flows, we have largely completed and extended the "Trade and Production 1976-1999" data set from the World Bank (Nicita and Olarreaga, 2001) using the new CEPII world database for international trade analysis at the product-level, $\mathrm{BACl}^{3}{ }^{3}$ We use also more recent versions of UNIDO data for production figures and end up with 105 importers annually reporting their imports from 135 exporters $^{4}$, over 25 years (1976-2000). All data used in this paper is available at http://www.cepii.fr/anglaisgraph/bdd/TradeProd.htm.

Secondly, we consider that relying on industry-level data is a prerequisite. Instead of using GDPs, we rely on industry level data for production and consumption within 26 ISIC industries. In total, we rely on a $105 \times 135 \times 26 \times 25$ matrix of potential trade flows. Note however that certain reporting countries failed to report their imports or production figures for certain years; accordingly, 105 reporters is a maximum. For comparison, Baier and Bergstrand (2004) rely on $96 \times 95 \times 5$ potential observations minus the zero flows. The two differences are that they rely on a panel with only 5 years $(1960,1970,1980,1990,2000)$ and have less zeros since they rely on total exports, rather than on sectoral exports.

Thirdly, we begin the regressions introducing one single dummy for all PTAs considered (see TABLE 1). However, it is important to tackle separately the impact of each PTA, since not all PTAs will have the same effects, in particular in absence of information as their exact content. We identify six different regional agreements: EU, NAFTA, ASEAN, MERCOSUR, Andean Community, CACM. The huge differences among these agreements are obvious regarding the level of economic integration of their members.

Fourthly, we must take into account not only the existence of a PTA, but also the level of tariff barriers. Here, we rely on bilateral tariff data based on an aggregation of TRAINS HS6 tariff data for some 5,000 products in our 26 industries using the world imports as weights for HS6 products. Even in manufactured goods and between industrialized countries, tariffs are not negligible and vary quite substantially across industries and country combinations.

In addition to these prerequisites, purely econometric issues have to be tackled regarding i) the issue of constraining the elasticity of trade flows to production to one; and ii) the use of fixed (vs random) effects by pair of countries in order to control for all unobservable determinants of PTAs.

The first step is to run simple gravity estimates using our panel of industry-level data. Instead of relying on traditional GDPs of countries $i$ and $j$ as proxies for demand in $i$ and supply capacity in $j$, we use the information on demand in sector $k$ of country $i$, and on supply of country $j$ in the same sector. Using such information will leave us more confident with the

3. As the original trade data, BACl is based on COMTRADE from the United Nations. See http://www.cepii.fr/anglaisgraph/bdd/baci.htm

4. Accordingly, CIF ${ }^{M i j}$ imports of the 30 non-reporting countries are inferred from the corresponding exports, $X_{i j}$, reported by the 105 reporters; the corresponding value is inflated by a 10 percent CIF/FOB factor, in line with DOTS indications. 
Table 1 - Preferential trade agreements

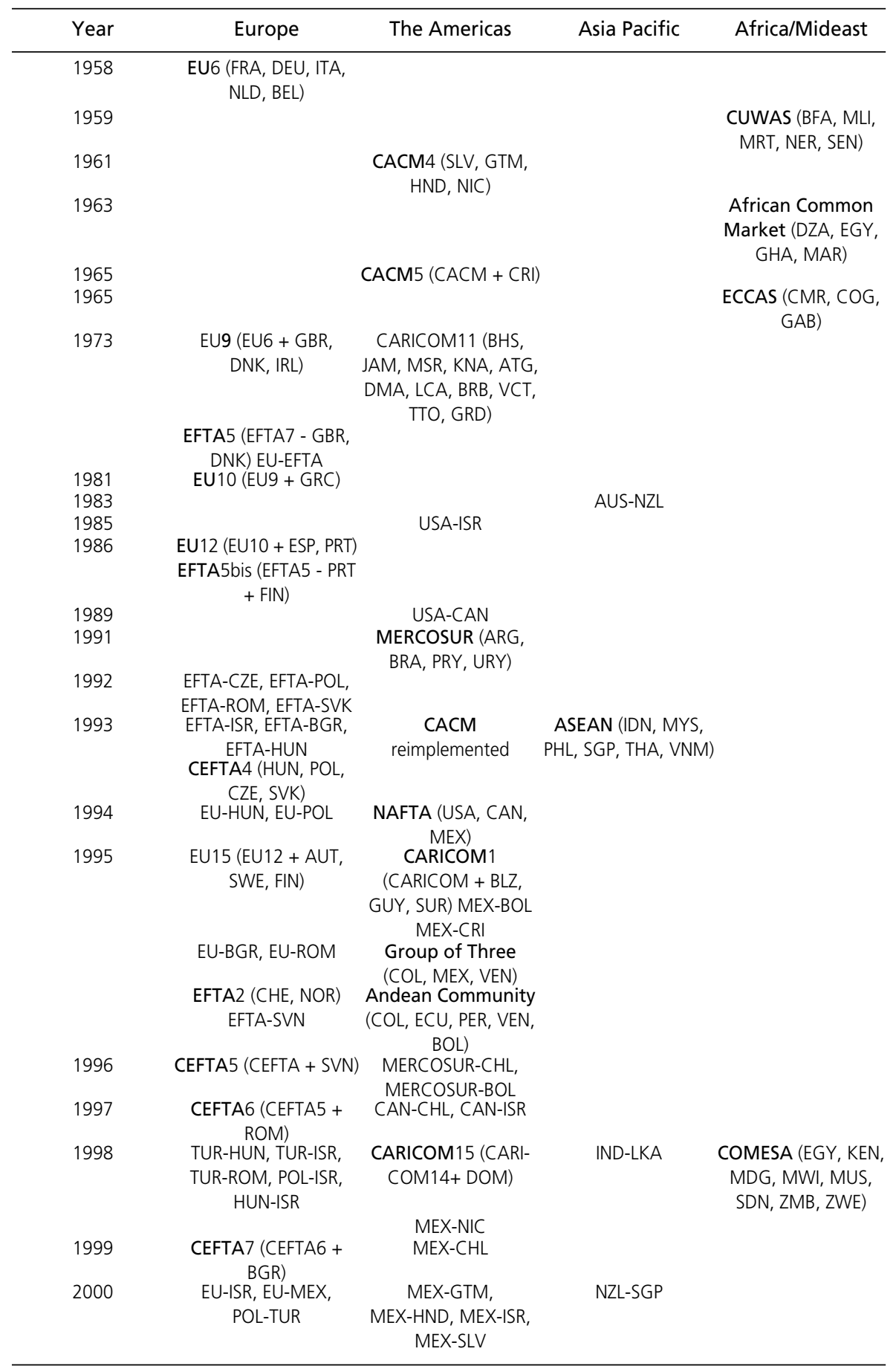

Source : Adapted from Frankel et al. (1997), Baier and Bergstrand (2004), http://www.caricom.org/ and http://www.cefta.org/. 
use of a disaggregated gravity equation. Except in column 3 of TABLE 2, we keep internal flows in the regressions for the sake of comparison with results using the border effect methodology in the next section. The deficit of international trade with respect to intranational trade is captured by the Border dummy.

In the first column of TABLE 2, we accordingly have a simple gravity equation explaining imports of country $i$ from provider $j$ in sector $k$ in year $t$, on the basis of production in $j$, consumption in $i$, transport cost between $i$ and $j$ proxied by their distance, plus additional variables generally used in such exercises: namely contiguity, common language, common colonizer, colonial link, and whether jurisdictions $i$ and $j$ belong or not to the same country in the past. Internal trade flows (e.g. products of a given sector shipped from Belem to Brasilia in a given year) are taken into account, in addition of "traditional exports". We lastly introduce a proxy taking the value 1 if a PTA is signed between $i$ and $j$ and 0 otherwise.

All parameter estimates have the expected sign and are significant at the 1 percent level, with the exception of the variable "same country". The magnitude of the coefficients on production and consumption is substantially lower than the expected unit elasticity, but in line with comparable estimates of the literature. The value of the parameter for the dummy PTA is 0.94 , corresponding to a 155 percent increase in trade for countries having signed an agreement. Accordingly, PTAs increase trade between members; however, one should not put too much confidence in such estimates for the reasons emphasized above. In particular, there are enormous differences in the content of the PTAs, and pooling the effects of the EU with those of the Andean community hardly makes sense.

In column 2, we accordingly replace the variable PTA, which covers all PTAs signed by countries considered here, by 6 selected PTAs, in order to compare the effects of these main different agreements. The interesting and expected result is the very large difference in the value of the parameter estimate for PTAs, which are all significant at the 1 percent level. It ranges from 0.48 (Andean Community) to 2.36 (NAFTA), discouraging from using a single dummy for all kinds of PTAs. Interestingly, the hierarchy of parameter values among PTAs seems not to be linked to the depth of the integration scheme: the parameter obtained for the EU is for instance similar to the one obtained for ASEAN.

In column 3, we replicate the previous estimation, excluding internal flows and hence also the border variable. Results are not significantly modified, which shows that coefficients on other covariates do not depend on the inclusion of internal trade flows. This is important since this set of observations is particular in several aspects. The dependent variable is constructed out of production and trade data, instead of directly measured from trade statistics. Also the construction of internal distance has to rely on specific assumptions, which possibly introduces bias in the distance coefficient and related variables like contiguity or PTAs which have a clear relationship to geographical proximity. 
In columns 4 and 5, we proceed with external as well as internal trade flows for each country. ${ }^{5}$ In all columns the value of the Border dummy is negative and very large: crossing a border dramatically reduces trade. The other parameter estimates of column 4 are very similar with the ones obtained in column 2, including the one concerning our 6 dummies for PTAs.

We introduce tariffs in column 4. Note that we lose a large number of observations in this column due to availability of tariff data, which only starts to be reasonably available in the beginning of the nineties. The coefficient on tariffs implies a reasonable average price elasticity for our sample. We observe a reduction in the value of the parameter for Border and for all PTAs when trade policy is taken into account (excepted the coefficient for the Central American Common Market, which is not significantly different from the estimate of column 2). Indeed, comparing columns 2 and 4, there is a dramatic reduction in the (large) trade effect of the EU: the trade surplus between members becomes $242 \%$ instead of $431 \%$ in the second column. Accordingly, when tariffs are taken into account (which is generally not done in such studies) the trade effects of ASEAN become larger than those of the EU.

Last, in column 5, we constrain the elasticity on production and consumption to take the value of one, as predicted by the theoretical model. The hierarchy of positive trade impacts of PTAs is now profoundly affected, which is not surprising given the estimated coefficients obtained on production and, particularly, on consumption variables, too different from 1. ASEAN becomes the most successful PTA, while the EU is the least trade-creating arrangement. Those results can be interpreted as a sign that imposing a unitary constraint on the production variable is doing too much violence to the actual patterns of trade. ${ }^{6}$ Alternatively, it can be understood as a sign that the estimates of regional arrangements are quite sensitive to the precise specification chosen. ${ }^{7}$ Once again, one should however not draw too rapid conclusions from such results given the myriad of problems associated with such strategies of estimation. Noticeably, we have not addressed so far the important endogeneity issue.

To put these initial findings into a nutshell, the estimation of the trade impact of regional arrangements remains highly unstable and seems hardly convincing. A possible reason for this is that results reported here are based on the right data, but introduced in a wrong specification. Acknowledgebly, one might argue that taking into account what we considered as

5. Note however that we do not (yet) rely on "structural" equation(4) below at this stage, but simply estimate a classical gravity equation, simply using more detailed data than it is generally done.

6 . When the same equations are estimated on the same database but aggregated keeping only the bilateral dimension, the results for production and consumption are closer to 1 (1.03 and 0.92 respectively for the fourth specification) and thus the coefficients of PTA dummies are more stable.

7. The comparison with results not using sectoral data, suggests that the impact of PTAs is accentuated when we work with disagregated data. The surplus of trade between member countries of one of the six selected agreements is reduced from $426 \%$ to $144 \%$ when data has only the bilateral dimension. 
the right benchmark, namely internal flows, does not fundamentally change the picture, as exemplified by the comparison of parameter estimates in columns 2 and 3. But as the next section will stress, as soon as we rely on a sound theoretical basis, one needs to introduce price indices; and since those prices are not observable, we must turn to relative imports in order to drop this term. This will be our first attempt to properly address the trade impact of the various PTAs, as reported in the next section. The endogeneity of trade arrangements issue is treated in section 4.

\section{THE RIGHT BENCHMARK FOR INTEGRATION}

International trade flows are not sufficient to gauge international markets integration. The measure of the degree of international fragmentation of markets is therefore by nature linked to the assessment of the impact of national borders. In Europe, this has been best summarized as the whole idea of the Single Market, which explicitly states its goal to be the abolition of the economic significance of national borders, in particular as far as prices are concerned.

In order to make that assessment, one needs to consider not only international trade flows but also flows of goods inside each country and see how they compare. However, in order to do a comparison between internal and external trade flows, ceteris paribus, the gravity approach should be adapted (McCallum, 1995 and Wei, 1996, are the seminal papers), in a more rigorous way than in the above estimation.

To that purpose, the border effects methodology offers important advantages for the study of regional integration. For a lot of issues, the border effect measure is a useful methodology because it captures all impediments to trade related to the existence of national borders, through their impact on trade flows. Accordingly, all hidden determinants associated with internal regulations impacting trade flows will be controlled for.

Also, border effects are more informative in the study of the evolution of trade barriers. In a traditional gravity equation, using a dummy variable for trade taking place inside a given PTA, how should we interpret a rise in the coefficient of this dummy variable? Using the traditional Vinerian interpretation of regional integration, this rise can first come from trade creation; the rise can however also come from a trade diversion. The gravity equation in its most traditional form (and even in more elaborated forms like Fukao et al., 2003, and in recent papers) find it hard to differentiate among the two causes, whereas border effects methodology enables to track a potential fall in the surplus of trade taking place inside countries, and therefore separate the trade creation from trade diversion effect. John Romalis (2002) provides an intermediate approach, where a bilateral trade equation of US imports is first run, and US imports from self are then used to compute trade diversion effects of NAFTA and CUSFTA. Let us first explain why relying on a border effect methodology is justified from a theoretical point of view. 
Table 2 - $\quad$ Simple gravity with sectoral panel data

\begin{tabular}{|c|c|c|c|c|c|}
\hline \multirow{2}{*}{ Model } & \multicolumn{5}{|c|}{ Dependent variable: In imports } \\
\hline & (1) & $(2)$ & (3) & (4) & (5) \\
\hline \multirow[t]{2}{*}{ Intercept } & $-0.84^{\mathrm{a}}$ & $-0.83^{a}$ & $-6.46^{a}$ & $-1.26^{\mathrm{a}}$ & $-8.93^{a}$ \\
\hline & $(0.03)$ & $(0.03)$ & $(0.03)$ & $(0.07)$ & $(0.02)$ \\
\hline \multirow[t]{2}{*}{ Border } & $-5.76^{\mathrm{a}}$ & $-5.76^{a}$ & & $-5.10^{\mathrm{a}}$ & $-5.46^{\mathrm{a}}$ \\
\hline & $(0.02)$ & $(0.02)$ & & $(0.05)$ & $(0.02)$ \\
\hline \multirow[t]{2}{*}{6 PTA } & $1.66^{\mathrm{a}}$ & & & & \\
\hline & $(0.01)$ & & & & \\
\hline \multirow[t]{2}{*}{ Other PTA } & $1.14^{\mathrm{a}}$ & $1.14^{\mathrm{a}}$ & $1.10^{a}$ & $0.53^{a}$ & $0.64^{a}$ \\
\hline & $(0.01)$ & $(0.01)$ & $(0.01)$ & $(0.02)$ & $(0.01)$ \\
\hline \multirow[t]{2}{*}{ Contiguity } & $0.77^{\mathrm{a}}$ & $0.76^{\mathrm{a}}$ & $0.72^{a}$ & $0.81^{\mathrm{a}}$ & $0.56^{\mathrm{a}}$ \\
\hline & $(0.01)$ & $(0.01)$ & $(0.01)$ & $(0.03)$ & $(0.01)$ \\
\hline \multirow[t]{2}{*}{ Common language } & $0.66^{a}$ & $0.67^{a}$ & $0.67^{a}$ & $0.80^{a}$ & $0.79^{a}$ \\
\hline & $(0.01)$ & $(0.01)$ & $(0.01)$ & $(0.02)$ & $(0.01)$ \\
\hline \multirow[t]{2}{*}{ Colonial link } & $0.80^{\mathrm{a}}$ & $0.80^{\mathrm{a}}$ & $0.79^{a}$ & $0.75^{a}$ & $0.41^{\mathrm{a}}$ \\
\hline & $(0.01)$ & $(0.01)$ & $(0.01)$ & $(0.03)$ & $(0.01)$ \\
\hline \multirow[t]{2}{*}{ Same country } & 0.00 & $0.05^{b}$ & 0.03 & $0.35^{a}$ & $0.28^{a}$ \\
\hline & $(0.02)$ & $(0.02)$ & $(0.02)$ & $(0.05)$ & $(0.03)$ \\
\hline \multirow[t]{2}{*}{ Common colonizer } & $0.58^{\mathrm{a}}$ & $0.58^{\mathrm{a}}$ & $0.58^{\mathrm{a}}$ & $0.85^{\mathrm{a}}$ & $1.43^{\mathrm{a}}$ \\
\hline & $(0.01)$ & $(0.01)$ & $(0.01)$ & $(0.03)$ & $(0.01)$ \\
\hline \multirow[t]{2}{*}{ Production } & $0.76^{\mathrm{a}}$ & $0.76^{\mathrm{a}}$ & $0.77^{a}$ & $0.80^{a}$ & 1 \\
\hline & $(0.00)$ & $(0.00)$ & $(0.00)$ & $(0.00)$ & \\
\hline \multirow[t]{2}{*}{ Consumption } & $0.56^{a}$ & $0.56^{\mathrm{a}}$ & $0.56^{a}$ & $0.53^{a}$ & 1 \\
\hline & $(0.00)$ & $(0.00)$ & $(0.00)$ & $(0.00)$ & \\
\hline \multirow[t]{2}{*}{ Distance } & $-0.72^{\mathrm{a}}$ & $-0.72^{\mathrm{a}}$ & $-0.75^{a}$ & $-0.74^{a}$ & $-0.92^{\mathrm{a}}$ \\
\hline & $(0.00)$ & $(0.00)$ & $(0.00)$ & $(0.01)$ & $(0.00)$ \\
\hline \multirow[t]{2}{*}{ EU } & & $1.67^{\mathrm{a}}$ & $1.62^{a}$ & $1.23^{\mathrm{a}}$ & $0.68^{a}$ \\
\hline & & $(0.01)$ & $(0.01)$ & $(0.02)$ & $(0.01)$ \\
\hline \multirow[t]{2}{*}{ NAFTA } & & $2.52^{a}$ & $2.50^{a}$ & $2.20^{a}$ & $0.79^{a}$ \\
\hline & & $(0.07)$ & $(0.07)$ & $(0.09)$ & $(0.08)$ \\
\hline \multirow[t]{2}{*}{ ASEAN } & & $1.69^{a}$ & $1.66^{\mathrm{a}}$ & $1.61^{\mathrm{a}}$ & $1.27^{\mathrm{a}}$ \\
\hline & & $(0.05)$ & $(0.05)$ & $(0.09)$ & $(0.06)$ \\
\hline \multirow[t]{2}{*}{ MERCOSUR } & & $1.42^{\mathrm{a}}$ & $1.41^{\mathrm{a}}$ & $0.91^{\mathrm{a}}$ & $1.21^{\mathrm{a}}$ \\
\hline & & $(0.11)$ & $(0.11)$ & $(0.14)$ & $(0.12)$ \\
\hline \multirow[t]{2}{*}{ CAN } & & $0.66^{\mathrm{a}}$ & $0.66^{a}$ & $0.35^{\mathrm{a}}$ & $1.26^{\mathrm{a}}$ \\
\hline & & $(0.06)$ & $(0.06)$ & $(0.08)$ & $(0.07$ \\
\hline \multirow[t]{2}{*}{ CACM } & & $1.68^{a}$ & $1.66^{\mathrm{a}}$ & $1.71^{\mathrm{a}}$ & $2.98^{a}$ \\
\hline & & $(0.05)$ & $(0.05)$ & $(0.15)$ & $(0.06)$ \\
\hline \multirow[t]{2}{*}{$\operatorname{Ln}(1+$ tariff $)$} & & & & $-2.70^{a}$ & \\
\hline & & & & $(0.05)$ & \\
\hline $\mathrm{N}$ & 1250558 & 1250558 & 1221585 & 245668 & 1250558 \\
\hline$R^{2}$ & 0.536 & 0.536 & 0.491 & 0.560 & 0.275 \\
\hline RMSE & 2.491 & 2.491 & 2.515 & 2.449 & 2.721 \\
\hline
\end{tabular}

Note: Standard errors in parentheses: ${ }^{a}, b^{b}$ and ${ }^{c}$ represent respectively statistical significance at the $1 \%, 5 \%$ and $10 \%$ levels. The reported standard errors take into account the correlation of the error terms for a given importer. 


\section{The link with theory}

In order to better address the issues raised in the previous section, the key issue of the empirical specification of the gravity equation has to be reconsidered. All empirical specifications should be guided (at least crudely) by theoretical analysis. This is how we will proceed below.

Complete reviews of how trade theory can yield gravity-type predictions are to be found in Feenstra (2003) and Anderson and van Wincoop (2004). One of the most convincing theoretical foundation of the gravity model is the Dixit-Stiglitz-Krugman model of trade under monopolistic competition and iceberg trade costs. It yields the following equation:

$$
M_{i j}=n_{j} p_{i j} c_{i j}=n_{j} p_{j}^{1-\sigma} \tau_{i j}^{1-\sigma} E_{i} P_{i}^{\sigma-1}
$$

where $n_{j}$ designate the number of varieties and $p_{j}$ the mill price in $j, E_{i}$ and $P_{i}=\left(\sum_{k} n_{k} p_{k}^{1-\sigma} \tau_{i k}^{1-\sigma}\right)^{1 /(1-\sigma)}$ are the expenditure and the "price index" in $i$, respectively.

We can see from (2) that trade costs influence demand more when there is a high elasticity of substitution, $\sigma$. Following Head and Mayer (2000), we take the ratio of $m_{i j}$ over $m_{i i}$ country i's imports from itself, the $\mu_{i} Y_{i} P_{i}^{\sigma-1}$ term then drops and we are left with relative numbers of firms, relative preferences, and relative costs in $i$ and $j$ :

$$
\frac{m_{i j}}{m_{i i}}=\left(\frac{n_{j}}{n_{i}}\right)\left(\frac{a_{i j}}{a_{i i}}\right)^{\sigma-1}\left(\frac{p_{j}}{p_{i}}\right)^{1-\sigma}\left(\frac{\tau_{i j}}{\tau_{i i}}\right)^{\sigma-1}
$$

We will refer below to this specification as explaining "relative imports".

To estimate (3), we need to specify more fully the model. The first step is to use the supply side characteristics of the monopolistic competition model. Firms producing $q_{j}$ in country $j$ employ $l_{j}$ workers in an IRS production function $l_{j}=F+\gamma q_{j}$, where $F$ is a fixed (labour) costs, and $\gamma$ the inverse productivity of firms. Profits are $\pi_{j}=p_{j} q_{j}-w_{j}\left(F+\gamma q_{j}\right)$ with $w_{j}$ the wage rate in $j$. Using the pricing equation, together with the free entry condition, we get the equilibrium output of each representative firm, $q_{j}=\frac{F(\sigma-1)}{\gamma}$. With identical technologies, $q_{j} \equiv q, \forall j=1 \ldots N$ and noting $v_{j}$ the value of production for the considered industry in $j_{1} v_{j}=q p_{j} n_{j}$, and we get the first substitution to be made in equation (3): $\frac{n_{j}}{n_{i}}=\frac{v_{j}}{v_{i}} \frac{p_{i}}{p_{j}}$.

Finally, functional forms for trade costs $\left(\tau_{i j}\right)$ and preferences $\left(a_{i j}\right)$ have to be specified in order to get an estimable equation.

- Trade costs are a function of distance $\left(d_{i j}\right.$, which proxies for transport costs) and "borderrelated costs", which can consist of tariffs and/or broadly defined NTBs (quantitative restrictions, administrative burden, sanitary measures...). We note the ad valorem equivalent of all border-related costs brcij:

$$
\tau_{i j} \equiv d_{i j}^{\delta}\left(1+\operatorname{brc}_{i j}\right)
$$


We want to control for the impact of membership in PTAs and we observe some of the actual protection taking place between importing and exporting countries (bilateral applied tariffs). We assume the following structure for border-related costs, which vary across country pairs and depend on the direction of the flow for a given pair:

$$
1+\operatorname{brc}_{i j} \equiv\left(1+t_{i j}\right)\left(\exp \left[\eta E_{i j}+\theta \text { PTA }_{i j}\right]\right)
$$

In this specification, $t_{i j}$ denotes the ad valorem bilateral tariff. PTA $A_{i j}$ is a dummy variable set equal to 1 when $i(\neq j)$ and $j$ belongs to a regional integration agreement and $E_{i j}$ is the intercept. We expect $\theta>0$ to be the lowest of those parameters, which will be true if, all national borders impose transaction costs, with the minimum burden of those costs being between PTA members.

- Preferences have a random component $e_{i j}$, and a systematic preference component for goods produced in the home country, $\beta$. Sharing a common language, a common border, a common colonizer is assumed to mitigate this home bias. For the sake of simplicity we only introduce in the equation the effect of sharing a common language, but in the estimations we introduce more variables of bilateral affinity as contiguity, colonial links and common history. ${ }^{8}$

$$
a_{i j} \equiv \exp \left[e_{i j}-\left(\beta-\lambda L_{i j}\right)\left(E_{i j}+\text { PTA }_{i j}\right)\right] .
$$

$L_{i j}$ is set equal to one when two different countries share the same language. When $L_{i j}$ switches from 0 to 1 , home bias changes from $\beta$ to $\beta-\lambda$.

We obtain an estimable equation from the monopolistic Krugman (1980) competition equation with home bias. In its more general form, the estimated equation in the next sections will be:

$$
\begin{gathered}
\ln \left(\frac{m_{i j}}{m_{i i}}\right)=-(\sigma-1)[\beta+\eta]+\ln \left(\frac{v_{j}}{v_{i}}\right)-\sigma \ln \left(\frac{p_{j}}{p_{i}}\right)-(\sigma-1) \ln \left(1+t_{i j}\right) \\
-(\sigma-1) \delta \ln \left(\frac{d_{i j}}{d_{i i}}\right)+(\sigma-1) \lambda L_{i j}-(\sigma-1)[\theta-\eta] \operatorname{PTA}_{i j}+\varepsilon_{i j} \\
\text { with } \varepsilon_{i j}=(\sigma-1)\left(e_{i j}-e_{i j}\right) .
\end{gathered}
$$

As can be seen in equation (4), we need measures of distances between $\left(d_{i j}\right)$ and within $\left(d_{i i}\right)$ countries for the countries in the sample. Two potential problems arise: how to define internal distances within countries and how to make those constructed internal distances consistent with "traditional" international distances calculations? The second question is in fact crucial for obtaining a correct estimate of the border effect. Any overestimate of the internal/external distance ratio will yield a mechanic upward bias in the border effect estimate.

8. The "same country" variable is set to one if the two countries are the same state or were the same administrative entity for a long period. The "colonial link" dummy refers to countries that had a colonial link. The "common colonizer" dummy equals to one if countries had a common colonizer after 1945. 
We have developed a new database of internal and external distances ${ }^{9}$, which uses city-level data in the calculation of the distance matrix to assess the geographic distribution of population inside each nation. The basic idea is to calculate distance between two countries based on bilateral distances between cities weighted by the share of the city in the overall country's population. This procedure can be used in a totally consistent way for both internal and international distances, which solves the problems highlighted above. The database also contains the contiguity, common language, colonial relationship and common colonizer variables used in this paper.

In addition to data used in the previous section, we need now the relative prices. They are captured by the price level of GDP expressed relative to the United States. This data comes from the Penn World Tables v.6.1.

The constant of this regression $(-(\sigma-1)[\beta+\eta])$ gives the border effect of international trade for countries that do not belong to a PTA. Accordingly, we expect a very large estimated value for this parameter. It includes both the level of protection of the importing country $(\eta)$ and the home bias of consumers $(\beta)$. The coefficient on PTA $A_{i j}$ gives the additional volume of trade generated by the agreement.

\section{Results: border effects plus panel data}

We now turn to the estimated equations corresponding to our theoretical benchmark. Results reported in TABLE 3 correspond to estimations where the intercept is the estimate of the border effect. Production, consumption and distances are now considered in relative terms in order to drop the price index term. We keep contiguity, common language, colonial links and same country variables, and then proceed as previously. In column 1, we use a single dummy for all PTAs. In column 2 we disentangle PTAs. In column 3 we add information on bilateral tariffs, which is helpful to identify an elasticity we will rely on below. In column 4 we constrain the elasticity of the relative production to unity instead of the estimate around 0.75 in previous columns. In column 5 , we use non sectoral data.

All covariates bear the expected sign. Interestingly, the border effect is very large. There are explanations to be given here. Firstly, note that the border coefficient reports the border effect among countries that do not belong to a PTA. Accordingly, the effect is maximized: the level of border effects estimated for non-PTA countries here is roughly 16 times what would be observed within an integrated region such as the EU (exp(6.78)/exp $(6.79-2.81)=16.4)$. Secondly, this is a worldwide estimation, incorporating countries such as Tanzania and Pakistan, in addition to OECD members, which explains also this very high level. Thirdly, the individual border effect between each pair of countries is simply averaged in these pooled estimates, notwithstanding the economic size of the economic partners or the importance of the bilateral flow: the border effect between Tanzania and Pakistan bears the same weight in the

9. Available at http://www.cepii.fr/anglaisgraph/bdd/distances.htm. 
Table 3 - $\quad$ Border effects of PTAs

\begin{tabular}{|c|c|c|c|c|c|}
\hline \multirow{2}{*}{ Model } & \multicolumn{5}{|c|}{ Dependant variable: $\mathrm{Ln}$ relative imports } \\
\hline & (1) & (2) & (3) & (4) & (5) \\
\hline \multirow[t]{2}{*}{ Border } & $-6.78^{a}$ & $-6.79^{a}$ & $-5.81^{a}$ & $-6.04^{a}$ & $-5.63^{a}$ \\
\hline & $(0.03)$ & $(0.03)$ & $(0.06)$ & $(0.03)$ & $(0.31)$ \\
\hline \multirow[t]{2}{*}{6 PTAs } & $2.70^{\mathrm{a}}$ & & & & \\
\hline & $(0.02)$ & & & & \\
\hline \multirow[t]{2}{*}{ Other PTAs } & $1.90^{\mathrm{a}}$ & $1.90^{\mathrm{a}}$ & $1.02^{a}$ & $1.65^{a}$ & $1.46^{\mathrm{a}}$ \\
\hline & $(0.02)$ & $(0.02)$ & $(0.03)$ & $(0.02)$ & $(0.12)$ \\
\hline \multirow[t]{2}{*}{ Contiguity } & $1.12^{\mathrm{a}}$ & $1.13^{\mathrm{a}}$ & $1.05^{\mathrm{a}}$ & $0.75^{a}$ & $1.19^{a}$ \\
\hline & $(0.02)$ & $(0.02)$ & $(0.03)$ & $(0.02)$ & $(0.14)$ \\
\hline \multirow[t]{2}{*}{ Common language } & $0.42^{a}$ & $0.44^{\mathrm{a}}$ & $0.57^{a}$ & $0.49^{a}$ & $0.88^{a}$ \\
\hline & $(0.01)$ & $(0.01)$ & $(0.03)$ & $(0.01)$ & $(0.10)$ \\
\hline \multirow[t]{2}{*}{ Colonial link } & $1.13^{\mathrm{a}}$ & $1.11^{\mathrm{a}}$ & $1.06^{\mathrm{a}}$ & $1.18^{\mathrm{a}}$ & $1.35^{\mathrm{a}}$ \\
\hline & $(0.02)$ & $(0.02)$ & $(0.04)$ & $(0.02)$ & $(0.14)$ \\
\hline \multirow[t]{2}{*}{ Same country } & $0.08^{a}$ & $0.24^{a}$ & $0.46^{a}$ & $0.10^{a}$ & $0.36^{b}$ \\
\hline & $(0.02)$ & $(0.02)$ & $(0.05)$ & $(0.03)$ & $(0.16)$ \\
\hline \multirow[t]{2}{*}{ Common colonizer } & $0.73^{a}$ & $0.71^{a}$ & $1.14^{\mathrm{a}}$ & $0.75^{a}$ & $0.95^{\mathrm{a}}$ \\
\hline & $(0.02)$ & $(0.02)$ & $(0.06)$ & $(0.02)$ & $(0.22)$ \\
\hline \multirow[t]{2}{*}{ Rel. production } & $0.72^{a}$ & $0.72^{\mathrm{a}}$ & $0.75^{a}$ & 1 & $0.74^{a}$ \\
\hline & $(0.00)$ & $(0.00)$ & $(0.01)$ & & $(0.02)$ \\
\hline \multirow[t]{2}{*}{ Rel. price } & $-0.30^{a}$ & $-0.30^{a}$ & $-0.14^{a}$ & $-0.95^{\mathrm{a}}$ & 0.04 \\
\hline & $(0.01)$ & $(0.01)$ & $(0.02)$ & $(0.01)$ & $(0.08)$ \\
\hline \multirow[t]{2}{*}{ Rel. distance } & $-0.38^{a}$ & $-0.37^{a}$ & $-0.47^{a}$ & $-0.63^{a}$ & $-0.32^{\mathrm{a}}$ \\
\hline & $(0.01)$ & $(0.01)$ & $(0.02)$ & $(0.01)$ & $(0.09)$ \\
\hline \multirow[t]{2}{*}{ EU } & & $2.81^{a}$ & $2.06^{\mathrm{a}}$ & $2.59^{a}$ & $2.16^{a}$ \\
\hline & & $(0.02)$ & $(0.04)$ & $(0.02)$ & $(0.18)$ \\
\hline \multirow[t]{2}{*}{ NAFTA } & & $2.91^{a}$ & $2.26^{a}$ & $2.60^{a}$ & $2.38^{a}$ \\
\hline & & $(0.06)$ & $(0.07)$ & $(0.06)$ & $(0.18)$ \\
\hline \multirow[t]{2}{*}{ ASEAN } & & $2.24^{a}$ & $1.97^{a}$ & $2.19^{a}$ & $2.79^{a}$ \\
\hline & & $(0.08)$ & $(0.14)$ & $(0.08)$ & $(0.55)$ \\
\hline \multirow[t]{2}{*}{ MERCOSUR } & & $1.46^{a}$ & $0.76^{a}$ & $1.40^{\mathrm{a}}$ & $1.04^{\mathrm{a}}$ \\
\hline & & $(0.07)$ & $(0.10)$ & $(0.08)$ & $(0.24)$ \\
\hline \multirow[t]{2}{*}{ CAN } & & $0.53^{a}$ & $-0.09^{a}$ & $0.36^{a}$ & 0.20 \\
\hline & & $(0.07)$ & $(0.09)$ & $(0.07)$ & $(0.21)$ \\
\hline \multirow[t]{2}{*}{ CACM } & & $2.13^{a}$ & $2.26^{a}$ & $2.16^{a}$ & $1.92^{a}$ \\
\hline & & $(0.06)$ & $(0.15)$ & $(0.06)$ & $(0.22)$ \\
\hline \multirow[t]{2}{*}{$\operatorname{Ln}(1+$ tariff $)$} & & & $-4.29^{a}$ & & $-6.19^{a}$ \\
\hline & & & $(0.24)$ & & $(1.32)$ \\
\hline $\mathrm{N}$ & 1312425 & 1312425 & 274987 & 1312425 & 97329 \\
\hline$R^{2}$ & 0.456 & 0.457 & 0.493 & 0.237 & 0.208 \\
\hline RMSE & 2.675 & 2.674 & 2.598 & 2.783 & 2.68 \\
\hline
\end{tabular}

Note: Standard errors in parentheses: ${ }^{a},{ }^{b}$ and ${ }^{c}$ represent respectively statistical significance at the $1 \%, 5 \%$ and $10 \%$ levels. The reported standard errors take into account the correlation of the error terms for a given importer. 
estimation as the one between the U.S. and Japan. Fourth, taking the tariff equivalent of such border effects would lead to reasonable magnitudes.

Introducing tariffs in the third column seriously erodes the positive impact of the PTAs we consider here. The implied price elasticity is 5.29, quite in line with recent estimates by Hanson (2005) or Head and Ries (2001) using somehow different methods. Using this price elasticity, we can calculate the tariff equivalent of the border effects estimated here. The tariff equivalent of crossing a border outside a PTA is $\exp (5.81 / 4.29)-1=287 \%$, while it amounts to $\exp ((5.81-2.06) / 4.29)-1=140 \%$ within the EU. These tariff equivalents are largely reduced when we run the same regression on non-sectoral data, they become respectively $148 \%$ and $75 \%$ (column 5 ).

What about the puzzling evidence obtained in the previous section regarding the hierarchy of trade effects of various PTAs? Contrary to previous findings, we obtain now a positive impact of the EU on trade flows which is much more in line with what should be expected. In particular, it is at least not inferior to the one estimated for the NAFTA, and it is larger than for ASEAN or for MERCOSUR, for instance. But still, is it matched by NAFTA in one of the estimations, which remains quite surprising at first sight.

\section{Are P'TAs exogenous?}

Another source of concern is the interpretation of the effect of the PTA dummies. Signing a preferential trade arrangement or a free trade zone agreement is not an event that should be modeled as an exogenous shock happening to certain pairs of countries and not to others. As Baier et Bergstrand (2004) show, PTAs are of course not exogenous, and depend on determinants that potentially also affect trade and are sometimes unobservable to the econometrician. The omitted variable bias is an important question, which has been neglected altogether until quite recently (see Carrère, 2005, for a recent implementation of techniques comparable to the ones used below). It raises questions about controlling for those unobservables, potentially finding instruments for the signature of PTAs and thinking about what a reasonable counterfactual is.

FIGURE 1 reports estimates of the first column of results of the previous section in which we have introduce dummies representing the 12 years preceding and following the signature of the agreement. More precisely, we introduce 25 dummies such as $P T A_{i j t}(0)$ equal to 1 if in the year $t$ an agreement is signed between countries $i$ and $j, \operatorname{PTA}_{i j t}(-1)$ is 1 if in the year $t-1$ an agreement begins between $i$ and $j$ and so on. The FIGURE 1 shows the estimates and standard errors of these dummies. On average, members of a PTA trade more than twice the norm during the 12 years preceding the agreement. The figure suggests also that the PTA changes the trend with an increase of the trade creating effect after the agreement: members trade five times more in the six years following the agreement.

Main determinants of the decision of signing a trade agreement may impact also trade volumes: geographical and cultural proximity tend to increase both. In Baier and Bergstrand 


\section{Figure 1 - $\quad$ Trade effects of a PTA}

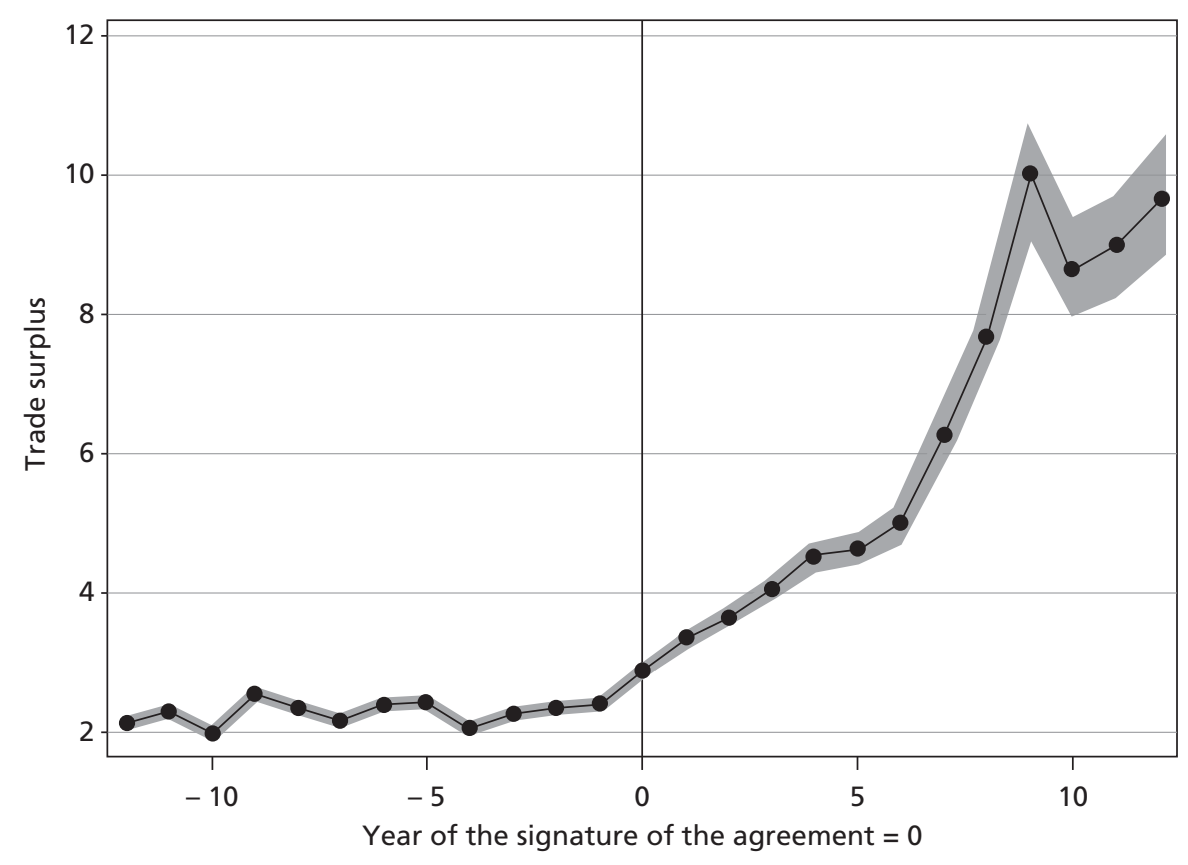

(2004), bilateral distances for instance explain more than $50 \%$ of the decision of signing a PTA in their first probit regression. Distance also explains trade patterns, but is controlled for in the trade equation, alleviating the endogeneity issue.

It is however quite likely that there are other simultaneous determinants of PTAs and trade that are not that so easy to observe. Bilateral trust between the two partners is an example of a variable that might affect both PTA signature and trade flows (see Guiso et al., 2005) and is almost impossible to observe on a large scale basis. When implementing empirically their hypothesis regarding what might drive the PTA signature decision, Baier and Bergstrand (2004) indeed find a list of covariates that explains an important part of the PTA decision. For a certain proportion of those unobservable characteristics, the bilateral structure is likely to be fixed over time, which suggests to introduce fixed effects for pairs of trade partners, as done in Carrère (2005). This specification allows to purge the coefficient on PTAs from bilateral fixed characteristics of countries that affect both PTAs and trade flows.

Therefore, as a third step, we introduce country-pair fixed effects, in order to identify the trade-impact of PTAs entirely on the time dimension, that is either comparing trade flows before and after the initial signature, or before and after entry in the PTA.

Column 1 in TABLE 4 is now simply replicating column 1 in TABLE 3 for the sake of comparison. In column 2, we introduce random effects and in column 3 fixed effects. Egger (2000) advocates in favor of the rejection of the random effects in the gravity model. However, we have 
Table 4 - $\quad$ Border effects of PTAs with fixed effects dyads

\begin{tabular}{|c|c|c|c|c|c|c|}
\hline \multirow{2}{*}{ Model } & \multicolumn{6}{|c|}{ Dependent variable : In relative imports } \\
\hline & OLS & RE & FE & OLS & RE & \\
\hline \multirow[t]{2}{*}{ Border } & $-6.78^{a}$ & $-6.84^{a}$ & $-7.62^{a}$ & $-6.79^{a}$ & $-6.84^{a}$ & $-7.61^{a}$ \\
\hline & $(0.03)$ & $(0.04)$ & $(0.00)$ & $(0.03)$ & $(0.04)$ & $(0.00)$ \\
\hline \multirow[t]{2}{*}{ Rel. Production } & $0.72^{\mathrm{a}}$ & $0.86^{\mathrm{a}}$ & $0.89^{a}$ & $0.72^{a}$ & $0.86^{\mathrm{a}}$ & $0.89^{a}$ \\
\hline & $(0.00)$ & $(0.00)$ & $(0.00)$ & $(0.00)$ & $(0.00)$ & $(0.00)$ \\
\hline \multirow[t]{2}{*}{ Rel. Price. } & $-0.30^{\mathrm{a}}$ & $-0.64^{\mathrm{a}}$ & $-0.62^{\mathrm{a}}$ & $-0.30^{\mathrm{a}}$ & $-0.64^{\mathrm{a}}$ & $-0.62^{\mathrm{a}}$ \\
\hline & $(0.01)$ & $(0.01)$ & $(0.01)$ & $(0.01)$ & $(0.01)$ & $(0.01)$ \\
\hline \multirow[t]{2}{*}{ Rel. Distance. } & $-0.38^{\mathrm{a}}$ & $-0.48^{\mathrm{a}}$ & & $-0.37^{\mathrm{a}}$ & $-0.48^{a}$ & \\
\hline & $(0.01)$ & $(0.01)$ & & $(0.01)$ & $(0.01)$ & \\
\hline \multirow[t]{2}{*}{ Contiguity } & $1.12^{\mathrm{a}}$ & $1.44^{\mathrm{a}}$ & & $1.13^{a}$ & $1.44^{\mathrm{a}}$ & \\
\hline & $(0.02)$ & $(0.10)$ & & $(0.02)$ & $(0.10)$ & \\
\hline \multirow[t]{2}{*}{ Common language } & $0.42^{\mathrm{a}}$ & $0.30^{a}$ & & $0.44^{\mathrm{a}}$ & $0.29^{a}$ & \\
\hline & $(0.01)$ & $(0.04)$ & & $(0.01)$ & $(0.04)$ & \\
\hline \multirow[t]{2}{*}{ Colonial link } & $1.13^{\mathrm{a}}$ & $1.34^{\mathrm{a}}$ & & $1.11^{\mathrm{a}}$ & $1.35^{\mathrm{a}}$ & \\
\hline & $(0.02)$ & $(0.10)$ & & $(0.02)$ & $(0.10)$ & \\
\hline \multirow[t]{2}{*}{ Same countries } & $0.08^{a}$ & $0.56^{a}$ & & $0.24^{a}$ & $0.45^{a}$ & \\
\hline & $(0.02)$ & $(0.16)$ & & $(0.02)$ & $(0.17)$ & \\
\hline \multirow[t]{2}{*}{ Common colonizer } & $0.73^{a}$ & $0.68^{a}$ & & $0.71^{a}$ & $0.69^{a}$ & \\
\hline & $(0.02)$ & $(0.07)$ & & $(0.02)$ & $(0.07)$ & \\
\hline \multirow[t]{2}{*}{6 PTAs } & $2.70^{a}$ & $1.21^{\mathrm{a}}$ & $1.16^{\mathrm{a}}$ & & & \\
\hline & $(0.02)$ & $(0.02)$ & $(0.02)$ & & & \\
\hline \multirow[t]{2}{*}{ Other PTAs } & $1.90^{\mathrm{a}}$ & $0.93^{\mathrm{a}}$ & $0.89^{a}$ & $1.90^{\mathrm{a}}$ & $0.92^{\mathrm{a}}$ & $0.88^{\mathrm{a}}$ \\
\hline & $(0.02)$ & $(0.02)$ & $(0.02)$ & $(0.02)$ & $(0.02)$ & $(0.02)$ \\
\hline \multirow[t]{2}{*}{ EU } & & & & $2.81^{a}$ & $1.19^{a}$ & $1.14^{\mathrm{a}}$ \\
\hline & & & & $(0.02)$ & $(0.02)$ & $(0.02)$ \\
\hline \multirow[t]{2}{*}{ NAFTA } & & & & $2.91^{a}$ & $1.32^{a}$ & $1.31^{\mathrm{a}}$ \\
\hline & & & & $(0.06)$ & $(0.08)$ & $(0.08)$ \\
\hline \multirow[t]{2}{*}{ ASEAN } & & & & $2.24^{a}$ & $1.05^{a}$ & $1.04^{a}$ \\
\hline & & & & $(0.08)$ & $(0.06)$ & $(0.06)$ \\
\hline \multirow[t]{2}{*}{ MERCOSUR } & & & & $1.46^{\mathrm{a}}$ & $1.30^{a}$ & $1.29^{a}$ \\
\hline & & & & $(0.07)$ & $(0.15)$ & $(0.15)$ \\
\hline \multirow[t]{2}{*}{ CAN } & & & & $0.53^{a}$ & $1.40^{\mathrm{a}}$ & $1.41^{\mathrm{a}}$ \\
\hline & & & & $(0.07)$ & $(0.07)$ & $(0.07)$ \\
\hline \multirow[t]{2}{*}{ CACM } & & & & $2.13^{a}$ & $1.91^{\mathrm{a}}$ & \\
\hline & & & & $(0.06)$ & $(0.40)$ & \\
\hline $\mathrm{N}$ & 1312425 & 1312425 & 1322590 & 1312425 & 1312425 & 1322590 \\
\hline$R^{2}$ & 0.456 & 0. & 0.182 & 0.457 & 0. & 0.182 \\
\hline RMSE & 2.675 & . & 2.285 & 2.674 & . & 2.285 \\
\hline
\end{tabular}

Note: Standard errors in parentheses: ${ }^{\mathrm{a}},{ }^{\mathrm{b}}$ and ${ }^{\mathrm{c}}$ represent respectively statistical significance at the $1 \%, 5 \%$ and $10 \%$ levels. The reported standard errors take into account the correlation of the error terms for a given importer. 
here an additional industry dimension that makes it more justifiable to test such specification. Interestingly, it permits to keep covariates which have only a bilateral (and no time) dimension, such as Contiguity for instance. When implemented, it appears that the choice between fixed and random effects does not significantly change the results. The main result is that the inclusion of fixed or random effects reduces drastically the value of the parameter estimate on PTAs: it is halved.

We conclude that on average, a large part of the trade effects of PTAs are due to unobservable characteristics of countries entering in such agreements. Instead of considering that, on average, trade is 5.7 times larger within a PTA, we find only a 2.4 increase when controlling for such unobservable country-pairs characteristics, that leaves only the effect on trade over the time dimension inside a given country pair that signs a PTA.

The same is true for the bulk of our sample: for the EU, NAFTA and ASEAN the impacts are overestimated when the bilateral (random) characteristics are omitted by a factor of around 2.4, 2.2 and 2.1 respectively. We conclude from this evidence that a large part of PTA membership's trade effects are simply artefacts: they fall drastically when we control for the endogeneity of the PTAs. To phrase it as a more provocative statement, it is because EU countries share the characteristics of countries intensively trading among themselves that they have formed the Common Market and subsequently the Single Market. But the trade effects of NAFTA, for instance, are much larger than the ones observed in Europe when such characteristics of member countries of the arrangement are taken into account.

\section{- Conclusion}

A huge literature using gravity equations to study bilateral volumes of trade has derived conclusions regarding the influence of regional agreements on trade patterns. Dozens of papers have analyzed almost all possible preferential trading agreements, looking for positive deviations from the "norm of trade" given by gravity. However, even the recent associated literature is relying on overall poor data, noticeably missing the industry dimension of the problem. Recent progress made in linking the empirical gravity equation and the different theoretical frameworks has sorted out serious shortcomings of such approach. In addition, one has to think about the reference group to which members of a PTA are compared since the endogeneity of the membership decision has been recently demonstrated.

This paper aimed at revisiting this literature by relying on richer data (sectoral data as well as internal trade flows or bilateral tariffs), by proposing an estimation strategy based on wellestablished theoretical bases, and last by trying to address the endogeneity issue. We first illustrate the profound variability of the trade impacts of the various PTAs. The idea that such differences would resume in the depth of the arrangements at stake hardly matches the hierarchy obtained here. Second, controlling for bilateral tariffs significantly reduces the impact of the EU which then becomes less "trade creating" than ASEAN in a traditional gravity equation. However, resorting to a border effect methodology leads to a more expected 
hierarchy in which the EU is among the most trade-impacting arrangements. Third, the endogeneity of PTAs recently documented in the literature proves to be a very serious issue: in particular, the endogeneity of the EU is ascertained when one controls for unobserved characteristics of country pairs, which consequently leads to a difficult assessment of the impact of the institutional arrangement per se.

L. F. \& S. Z. ${ }^{10}$

\section{REFERENCES}

Aitken, N., 1973. The effect of the EEC and EFTA on European trade: A temporal cross-section analysis, American Economic Review 63 (5), 881-92.

Anderson, J., van Wincoop, E., 2003. Gravity with gravitas: A solution to the border puzzle, American Economic Review 93 (1), 170-92.

Anderson, J., van Wincoop, E., 2004. Trade Costs, Journal of Economic Literature 42 (3), 691-751.

Baier, S., Bergstrand, J., 2004. Do free trade agreements actually increase members' international trade, mimeo, October.

Bouët, A., Decreux, Y., Fontagné, L., Jean, S., Laborde, D., 2004. A consistent, ad-valorem equivalent measure of applied protection across the world: The MAcMap-HS6 database, CEPII Working Paper 2004-22.

Carrère, C., 2006. Revisiting the effects of regional trade agreements on trade flows with proper specification of the gravity model, European Economic Review 50 (2), 223-47.

Chen, N., 2003. Intra-national versus international trade in the European Union: why do national borders matter?, forthcoming in the Journal of International Economics.

Disdier, A-C., Head, K., 2003. Exaggerated reports of the death of distance: Lessons from a metaanalysis, presented at the 2003 ETSG meetings in Madrid.

Eaton, J., Kortum, S., 2002. Technology, geography and trade, Econometrica 70 (5), 1741-80.

Egger, P., 2000. A note on the proper econometric specification of the gravity equation, Economics Letters 66, 25-31.

European Commission, 2003. The internal market - Ten years without frontiers, available at http://ec.europa.eu/internal_market/10years/docs/workingdoc/workingdoc_en.pdf.

Evenett, S., Keller, W., 2003. On theories explaining the success of the gravity equation, Journal of Political Economy 110 (2), 281-316.

Feenstra, R., 2003. Advanced International Trade: Theory and Evidence, Princeton: Princeton University Press.

Fontagné, L., Mimouni, M., 2001. L'environnement, nouvel obstacle au commerce de produits agricoles et alimentaires, Économie internationale 87 (3), 63-87.

10. We are grateful to Thierry Mayer, who worked with us on previous stages of this paper. We also thank the participants of conferences where this paper was presented: "Les nouvelles frontières de l'Europe" (Marrakech, March 2005); The International Trade Roundtable 2005; "The WTO at 10 Years: The Regional Challenge to Multilateralism" (Brussels, June 2005); "LIVth Annual Congress of AFSE" (Paris, September 2005); "10"th Annual Congress of LACEA" (Paris, October 2005); "New Regionalism : Progress, Setbacks and Challenges" (Third CEPII-IDB Conference, Washington, February 2006). 
Frankel, J.A., 1997. Regional Trading Blocs, Washington, DC: Institute for International Economics.

Frankel, J., Stein, E., Wei, S-J., 1995. Trading blocs and the Americas: The natural, the unnatural, and the supernatural, Journal of Development Economics 47 (1), 61-95.

Fukao, K., Okubo, T., Stern, R., 2001. An econometric analysis of trade diversion under NAFTA, North American Journal of Economics and Finance 14, 3-24.

Guiso, L., Sapienza, P., Zingales, L., 2005. Cultural biases in economic exchanges, CEPR Discussion Paper 4837.

Hanson, G., 2005. Market potential, increasing returns and geographic concentration, Journal of International Economics 67 (1), September, 1-24.

Haveman, J., Nair-Reichert, U., Thursby, J., 2003. How effective are trade barriers? An empirical analysis of trade reduction, diversion and compression, The Review of Economics and Statistics 85 (2), 480-85.

Haveman, J., Hummels, D., 1998. Trade creation and trade diversion: New empirical results, Journal of Transnational Management Development 3 (2), 47-72.

Head, K., Mayer, T., 2000. Non-Europe: The magnitude and causes of market fragmentation in Europe, Weltwirschaftliches Archiv 136 (2), 285-314.

Head, K., Ries, J., 2001. Increasing returns versus national product differentiation as an explanation for the pattern of US-Canada trade, American Economic Review 91 (4), 858-76.

Krugman, P., 1980. Scale economies, product differentiation, and the pattern of trade, American Economic Review 70 (5), 950-59.

Lai, N., Trefler, D., 2002. The gains from trade with monopolistic competition: Specification, estimation, and mis-specification, NBER Working Paper 9169.

McCallum, J., 1995. National borders matter: Canada-US regional trade patterns, American Economic Review 85 (3), June, 615-23.

Nicita, A., Olarreaga, M., 2001. Trade and production, 1976-99, World Bank Policy Research Working Paper 2701.

Nitsch, V., 2000. National borders and international trade: Evidence from the European Union, Canadian Journal of Economics 33 (4), 1091-1105.

Romalis, J., 2002. NAFTA's and CUSFTA's impact on North American trade, mimeo, University of Chicago Graduate School of Business, http://faculty.chicagogsb.edu/john.romalis/research/Research.htm; Review of Economics and Statistics, forthcoming, 2007.

Santos Silva, J.M.C., Tenreyro, S., 2004. The log of gravity, mimeo.

Soloaga, I., Winters, L.A., 2001. Regionalism in the nineties: What effect on trade?, North American Journal of Economics and Finance 12 (1), 1-29.

Trefler, D., 1993. Trade liberalization and the theory of endogenous protection: An econometric study of U.S. import policy, The Journal of Political Economy 101 (1), February, 138-60.

Wagner, D., 2003. Aid and trade-An empirical study, Journal of the Japanese and International Economies 17 (2), 153-73.

Wei, S-J., 1996. Intra-national versus international trade: How stubborn are nations in global integration?, National Bureau of Economic Research Working Paper 5531. 
